\title{
THE INFLUENCE OF CALCIUM AND BARIUM ON THE SECRETORY ACTIVITY OF THE KIDNEY. ${ }^{1}$
}

\author{
BY \\ JOHN BRUCE MACCALLUM, M. D. \\ From the Rudolph Spreckels Physiological Laboratory of the \\ University of California.
}

In previous publications ${ }^{2}$ it was shown that subcutaneous or intravenous injections of small quantities of solutions of certain salts, including the saline purgatives, produce not only increased peristalsis, but also an increased secretion of fluid into the intestine. This was found to be true also when the solutions were applied locally to the peritoneal surfaces of the intestine. It was suggested that the main actions of saline purgatives consist in the production of increased peristaltic movements, and of increased secretion of fluid into the intestine; and that the semifluid foeces which are produced by saline purgatives are the result not of decreased power of absorption by the intestine, but of an increased secretion of fluid into the intestine. It was further shown that the administration of calcium or magnesium chloride tends to suppress the peristaltic movements and the secretory activity of the intestine. Attention was specially called to the marked action of barium chloride in the production of violent peristaltic movements and ringlike constrictions in the intestine, and also in the production of an increased flow of fluid into the intestine. It was also pointed out that the production of these activities in the intestine by the purgative salts, and their suppression by calcium and magnesium is analogous to the production and suppression of rhythmical contractions in voluntary muscles de-

1 A preliminary report of these experiments was published in the University of California Publications, Physiology, January I5, 1904, Vol. I., No. 10, p. 8r.

2 MacCallum, J. B.-American Journal of Physiology, Vol. X., No. III., p. IOI, I903, and Vol. X, No. V, p. 259, I904. 
scribed by Loeb ${ }^{1}$. The antagonism which has been shown by Loeb to exist between the actions of many sodium salts on the one hand, and calcium and magnesium salts on the other was further illustrated by these experiments.

It seemed possible then in the light of these facts that the activities of the kidney might be controlled in the same way as those of the intestine. Since it is well known that many sodium salts have a distinct diuretic action, it seemed conceivable that calcium or magnesium might act as an antidiuretic. In order to decide this point I have made a series of experiments in which I have found that the relation of many of the salts to the activity of the kidneys is similar to that which they bear to the glandular activity of the intestine.

\section{METHODS.}

The following experiments were carried out mainly on rabbits; a few dogs also were used. In all cases morphine was given as an anaesthetic. The rabbits received 3-5 cc. r\% solution of morphine hydrochlorate subcutaneously; the dogs in addition to this dose of morphine were given ether when necessary.

The urine was collected by catheterising the ureters or by tying a cannula in the bladder. The latter method was employed in all cases except those in which it was necessary to observe the difference between the amounts secreted by the two kidneys. In placing a cannula in the bladder a small incision was made in the abdominal wall. The bladder, which usually contains a considerable quantity of urine, was then lifted out of the body cavity, and the abdominal wall sewed up around the neck of the bladder so that the intestines could not be forced out. A purse-string suture was then made in the fundus of the bladder and an incision made in the bladder wall within the suture. In this way the urine could be removed, and the cannula securely tied in. Care was taken to allow no urine to collect in the bladder, so that the measurements given in the tables represent all the urine that was secreted during each period. The simple catheterisation of the bladder through the urethra may be easily performed in rabbits,

1 LoEB, J.-Festschrift für Fick, I899; Archiv, für die gesammte Physiologie. 1902, XCl, p. 248 . 
but this method is unsatisfactory when it is necessary to obtain the exact amount of urine secreted in a given time since it is impossible to tell whether the bladder is at any time entirely empty.

Solutions of the salts whose actions were tested were introduced into the body intravenously. In rabbits a hypodermic needle was placed in a vein of the ear; in dogs the fluid was forced into one of the superficial veins of the lower limb. When small quantities were injected a hypodermic syringe was used; when larger amounts were introduced a pressure apparatus was employed. This was the apparatus commonly used in injection work, consisting of a pressure bottle connected on one side with a water tap, and on the other with a graduated bottle containing the solution to be injected. In this way a constant pressure could be obtained, and the quantity of fluid injected in a unit of time accurately controlled. By causing the fluid to pass through a coil of rubber tubing immersed in hot water before reaching the needle, the solution could be kept constantly at the body temperature. Some of the details of the apparatus were suggested to me by an apparatus used by Dr. M. H. Fischer in this laboratory. For such infusions into the blood only $\mathrm{m} / \mathrm{s}$ solutions were employed; in subcutaneous injections stronger solutions were used. Except in those cases where it was necessary to obtain the effect of the salt on the normal flow of urine, the secretion was considerably raised and kept constant by the uniform infusion of $\mathrm{m} / \mathrm{s} \mathrm{NaCl}$ solution throughout the experiment. The effect of the other salts was then obtained by allowing small quantities of $\mathrm{m} / \mathrm{s}$ solutions to flow into the vein along with the $\mathrm{NaCl}$ solution. In other instances these salts were injected into a vein of one ear while the $\mathrm{NaCl}$ solution was at the same time flowing into the opposite ear. In these experiments the ear of the rabbit was securely tacked to the board, and the needle kept from slipping out of the vein by means of bull-dog forceps.

\section{EXPERIMENTS.}

The results of the experiments on the actions of calcium and barium may be best seen in the following tables:

I. Dog-small terrier-cannula placed in right ureter.

Urine secreted in ist ro minutes.......... $3.6 \mathrm{cc}$. $2 \mathrm{~d}$ Io minutes.......... 3.6 " 
$8 \mathrm{cc}{ }^{\mathrm{m}} / 8 \mathrm{CaCl}_{2}$ injected into vein of leg.

Urine secreted in Ist Io minutes.... $\ldots \ldots \ldots 2.4 \mathrm{cc}$ $2 \mathrm{~d}$ ro minutes........... 2.2 " $3^{\mathrm{d}}$ ro minutes........... I.8 " $4^{\text {th }}$ ro mniutes........... r.6 " 5 th 10 minutes........... I.4 "

Io $\mathrm{cc}^{\mathrm{m} / \mathrm{2}}$ sodium citrate injected subcutaneously.

Urine secreted in Ist 10 minutes. . . . . . . . I.6 “ $2 \mathrm{~d}$ Io minutes........... 2.3 " 3d ro mniutes........... 3.I " $4^{\text {th }}$ ro minutes.......... $3.6^{\text {" }}$

In this case the secretion of urine gradually decreased after the injection of calcium chloride until the amount collected in a unit of time was less than half of the initial amount. The addition of sodium citrate to the blood counteracted this effect so that the rate of secretion again approached the normal. These effects are more striking when the quantity of urine secreted is increased by the introduction of normal salt solution into the blood as shown in the following experiment:

2. Rabbit-cannula placed in bladder. No urine flowed in the first or second periods of I o minutes before the $\mathrm{NaCl}$ solution was injected.

\begin{tabular}{|c|c|c|c|}
\hline Time. & $\begin{array}{l}\text { Salts other than } \\
\mathrm{NaCl} \text { injected. }\end{array}$ & $\begin{array}{l}{ }^{\mathrm{n}} / \mathrm{saCl} \text { in }- \\
\text { jected in cc. }\end{array}$ & $\begin{array}{l}\text { Urine in } \\
\text { cc. }\end{array}$ \\
\hline 10.10 & - & IO & - \\
\hline IO.I 5 & — & Io & - \\
\hline 10.20 & - & 5 & 0.5 \\
\hline 10.40 & - & IO & 0.8 \\
\hline II.OO & - & IO & 0.5 \\
\hline II. 20 & $\ldots$ & 5 & I. O \\
\hline I I.40 & - & IO & 2.8 \\
\hline 12.00 & & Io & 6.0 \\
\hline 12.00 & \multirow{2}{*}{\multicolumn{3}{|c|}{$\begin{array}{l}5 \mathrm{cc} \mathrm{m}^{\mathrm{m}} / 8 \mathrm{CaCl}_{2} \text { intravenously } \\
5 \mathrm{cc}^{5 \mathrm{~m} / \mathrm{CaCl}} \mathrm{CaCl}_{2} \text { subcutaneously }\end{array}$}} \\
\hline I 2.05 & & & \\
\hline 12.20 & - - - & 5 & 0.2 \\
\hline 12.40 & - & Io & I. 8 \\
\hline 1.00 & & Io & 0.8 \\
\hline I.OO & \multicolumn{3}{|c|}{$5 \mathrm{cc} \mathrm{m} / 8$ sodium citrate intravenously } \\
\hline 1.20 & & Io & 2.2 \\
\hline 1.40 & . & 5 & 3.6 \\
\hline
\end{tabular}


In this experiment, although the flow of urine has been considerably increased by the injection of $\mathrm{m} / \mathrm{s} \mathrm{NaCl}$, the introduction of $\mathrm{CaCl}_{2}$ markedly suppresses the secretion. The flow of urine remains small for an hour, although a somewhat greater quantity of fluid is forced into the blood than in the previous hour. This suppres sion of urine is at once counteracted by the injection of sodium citrate.

The following table (3) which represents only the latter half of an experiment shows roughly the duration of the action of smaller doses of calcium.

3. Rabbit-cannula in bladder-injections intravenous.

Time. Salts other than $\mathrm{m} / \mathrm{s} \mathrm{NaCl}$ in- Urine in
$\mathrm{NaCl}$ injected.

\subsection{5}

I I. $4 \mathrm{O}$

I I. 45

I I. $5^{\circ}$

I I. 55

I 2.00

I 2.05

I 2.05

I 2.10

I 2.15

I 2.20

I 2.25

I 2.30

I 2.35

I 2.40

I 2.45

I 2.50

I 2.55

As shown here and in other experiments, the action of calcium is only temporary. I have found also that magnesium chloride in many cases has an antidiuretic action similar to that of calcium chloride. The suppression of urine, however, is not so marked as with calcium.

As shown in the following experiment (4) barium chloride in very small doses has a strong diuretic action. Although it is much more powerful in this respect than sodium citrate, the increased flow of urine which it causes may be suppressed by the injection of calcium chloride. 
4. Rabbit; injections intravenous.

Time.

I 0.20

I0.30

I 0.40

I 0.50

I 1.00

I I. IO

I 1.20

I I. 30

II. 40

I I. 40

I 1.50

I 2.00

I 2.10

I 2.10

12.20

12.30

12.30

I 2.40

I 2.50

I.OO

I. IO

1.20

I. 20

I. 30

1.40

I. 50

I. 50

$\{1.55$

2.00

2. 10

2.20

2.30
Salts other than

$\mathrm{NaCl}$ injected. $\mathrm{m} / 8 \mathrm{NaCl}$ in- Urine in jected in cc. $\quad$ cc.

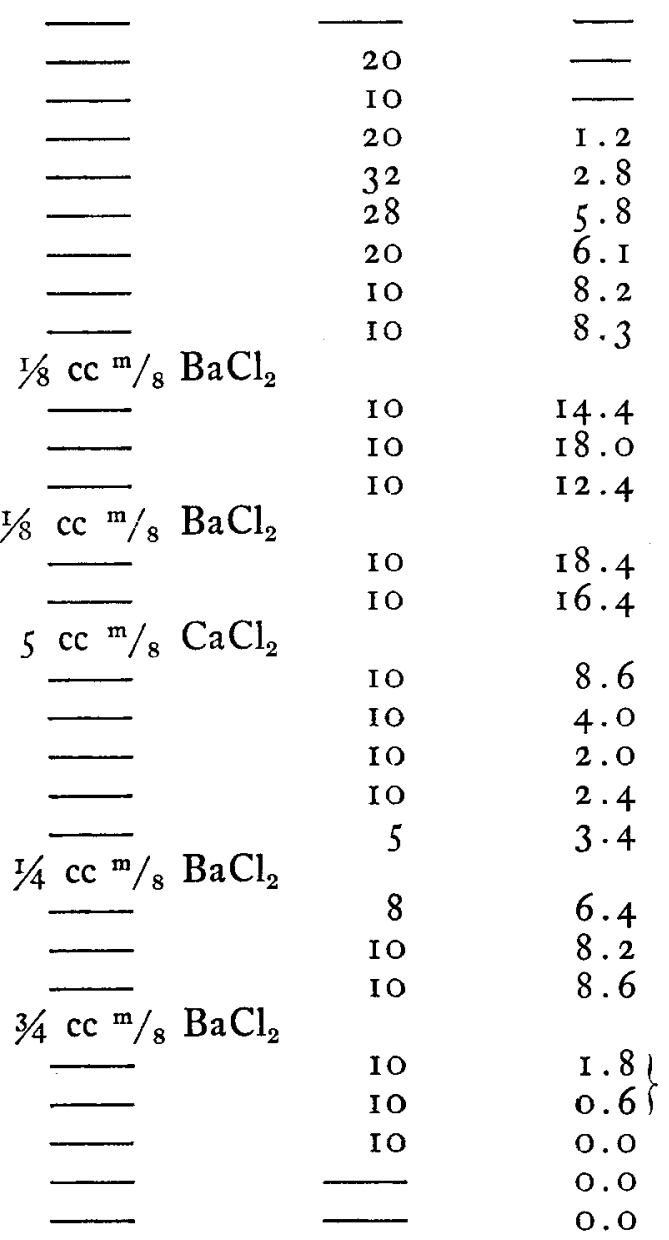

In the uniform injection of considerable quantities of normal salt solution into the blood, the flow of urine, after about an hour, becomes fairly constant. If an average amount of $\mathrm{I}$ cc. in I minute be introduced, the secretion of urine during the first two or three hours is usually slightly less than the amount of fluid injected. After this time, when no other salts have been added, the quantity injected and the quantity secreted may become 
approximately equal. As shown in experiment 4 however the addition of a minute quantity of $\mathrm{BaCl}_{2}$ (less than $\mathrm{I} / 2 \mathrm{cc} \mathrm{m} / 8$ solution) to the blood causes the flow of urine to increase markedly, so that the quantity secreted in a unit of time is far in excess of the quantity of fluid introduced into the blood. If, however, while this active secretion is going on, $5 \mathrm{cc} . \mathrm{m} / \mathrm{s} \mathrm{CaCl}_{2}$ solution be injected into the blood, the flow of urine rapidly decreases, although the total quantity of fluid added to the blood remains constant. The further addition of $\mathrm{BaCl}_{2}$ again increases the secretory activity so that the quantity secreted in Io minute periods which has fallen from 16.4 to 2 , under the influence of $\mathrm{CaCl}_{2}$ is again raised to 8.6 by the injection of the barium salt. An apparently contradictory thing, however, happens when a larger amount of barium chloride is suddenly added to the blood. As shown in the foregoing table, while $\mathrm{T} / 8 \mathrm{cc} . \mathrm{BaCl}_{2}$ largely increases the urinary secretion, the injection of $3 / 4 \mathrm{cc}$. in addition to that already present, causes an entire cessation of the flow of urine. In some cases this suppression of the flow of urine is quite abrupt; in other instances it is more gradual, a few drops of urine flowing from the cannula at intervals. As shown in the following experiment, the injection of $\mathrm{CaCl}_{2}$ sometimes counteracts this action of larger doses of $\mathrm{BaCl}_{2}$ and causes the urine to flow again.

5. Rabbit-cannula in bladder; injections intravenous.

Time.

Salts other than

$\mathrm{m} / \mathrm{s} \mathrm{NaCl}$ in- Urine in

$\mathrm{NaCl}$ injected. jected in cc.

cc.

\section{$9 \cdot 55$}

I 0.00

IO.I 5

I 0.30

I 0.45

I I. OO

I I .00

I I. I 5

I I. 30

I I 45

I I 45

I 2.00

I 2.15

I 2.30

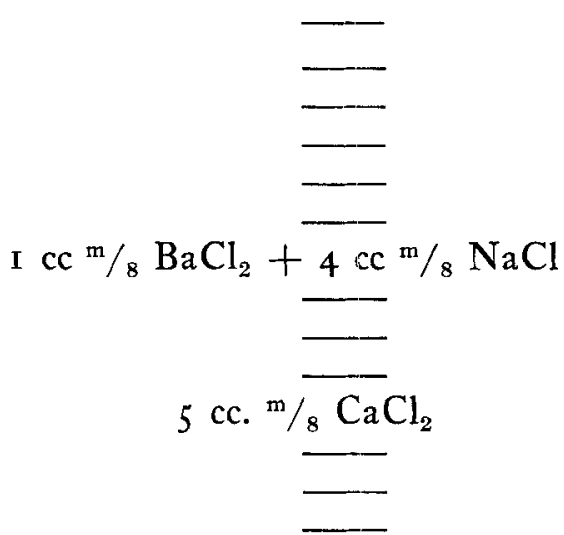

I O

I 5

I 5

I 5

I 5

Io

I 5

I 5

10

I 5
I . $O$

$3 \cdot 4$

5.2

$5 \cdot$ I

4.8

2.4

0.2

o. 3

2.0

$3 \cdot 8$

4.0 
In this case $\mathrm{I} \mathrm{cc} \mathrm{m} / \mathrm{s} \mathrm{BaCl}_{2}$ gradually suppresses the flow of urine, and no trace of the strong diuretic action of barium is seen. And, further, calcium chloride has here an action which seems at first glance entirely opposed to that which it ordinarily has. As shown in the previous experiments, calcium characteristically suppresses the secretion of urine. In this case the flow of urine increases after its administration. These apparent contradictions may be explained in the following way. In discussing the actions of calcium and barium on the intestine, it was pointed out that barium chloride, like the other saline purgatives, affects the intestine in two ways, namely, by increasing the peristaltic movements and by increasing the secretion of fluid into the lumen. Attention was further called to the violent character of the muscular contractions in the intestine caused by barium, which may so constrict the lumen of the intestine that fluid cannot pass from one part to another. It was also shown that calcium to some extent counteracts the action of barium both on the muscle, and on the glands of the intestine. It seems therefore probable that the increase in the flow of urine caused by small doses of barium chloride $(\mathrm{I} / 8 \mathrm{cc} . \mathrm{m} / \mathrm{s}$ solution) is due to an increase in the secretory activity of the kidney entirely analogous to that which is produced in the intestine by the same salt. The cessation of the flow of urine however which follows the administration of larger doses of barium chloride ( $\mathrm{Icc} . \mathrm{m} / \mathrm{s}$ solution) is in all probability due to the action of the barium on the muscle coats of the urinary passages, especially those of the calyces and pelvis of the kidney, and those of the ureter. Since all of these various parts of the urinary passages are surrounded by thick, circular and longitudinal muscle coats, not unlike those of the intestine, it seems conceivable that a strong contraction of these coats, such as barium is capable of causing in the intestine might effectually shut off the lumen so that no urine could pass. Furthermore the action of calcium in renewing the flow of urine under these circumstances is quite analogous to its action in suppressing the peristaltic movements or in relieving the constrictions in the intestine caused by barium. The actions of calcium and barium which are shown in Table 5, are on the muscle coats of the urinary passages. It is quite conceiv- 
able however that this action of calcium may coexist with its charasteristic action in diminishing the secretory activity of the kidney. In both the intestine and the urinary apparatus (kidney, and urinary passages) barium stimulates the glandular and the muscular tissues to activity. Calcium on the other hand uniformly suppresses these activities.

It must be pointed out however that the suppression of the flow of urine which follows a relatively large dose of barium chloride cannot always be relieved by calcium. As was found to be true in the intestine, the action of barium is seldom completely counteracted by calcium. In many cases the barium stops the flow of urine entirely so that it is not possible to start it again. This is shown in the following experiment (6) where relatively large quantities of calcium chloride are incapable of reëstablishing the flow of urine. This naturally suggests the idea that the large doses of barium may stop the secretion of urine by injuring the cells of the kidney, or perhaps indirectly by a constricting influence on the blood vessels. These possibilities must be taken into consideration; but the fact that calcium sometimes causes the urine to flow again after it has been inhibited by barium speaks strongly in favor of the theory advanced above, that the inhibiting action of barium on the flow of urine is an action on the muscular tissue of the urinary passages.

6. Rabbit-cannula in bladder; injections intravenous.

\section{Time.}

I 0.20

10.30

10.40

10.50

I I. OO

I I.IO

I I.2O

I I. 30

I I. 40

I $\mathrm{x} .5^{\circ}$

I I. 5 I

I I. 55
Salts other than $\mathrm{NaCl}$ injected. $\mathrm{m} / \mathrm{s} \mathrm{NaCl}$ in- Urine in jected in cc.
cc.

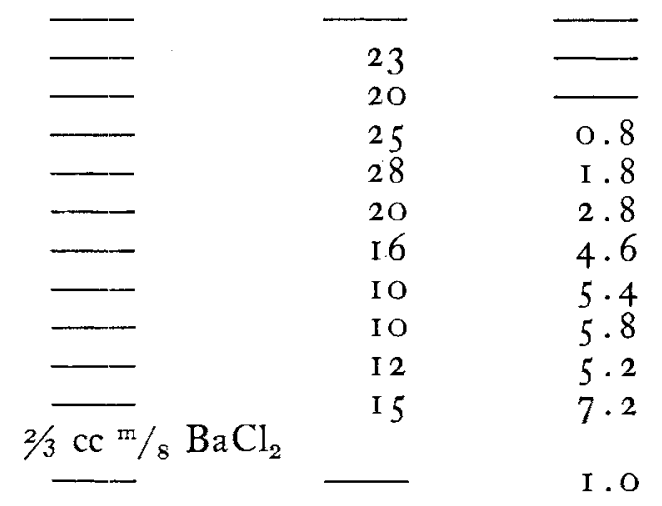




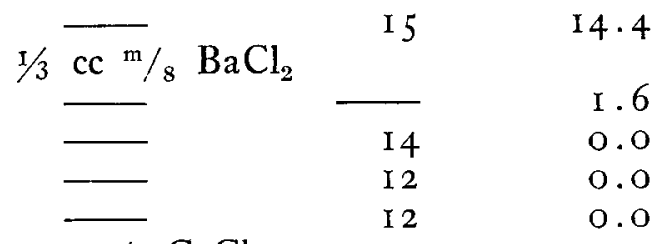

$$
\begin{aligned}
& 5 \mathrm{cc} \mathrm{m} / \mathrm{s} \mathrm{CaCl}_{2} \quad \text { I } 5 \quad 0.0
\end{aligned}
$$

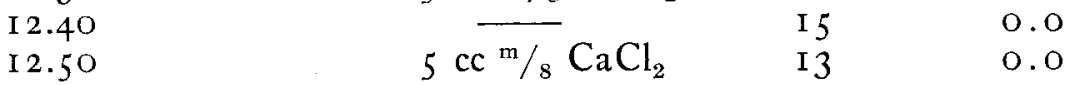

$$
\begin{aligned}
& \text { I.IO - I } \quad \text { I } \quad 0.0
\end{aligned}
$$$$
\text { I.00 }
$$$$
\text { I.20 }
$$

It will be noticed in this experiment (6) that immediately after the injection of $2 / 3 \mathrm{cc} .{ }^{\mathrm{m}} / 8 \mathrm{BaCl}_{2}$ solution there is a marked diminution in the flow of urine followed within a few minutes by a very considerable increase. This partial cessation of the flow immediately following the injection is due probably to a temporary action of the barium on the muscle coats of the urinary passages. The subsequent increase is the result of the diuretic action of barium on the kidney as described above.

In considering the actions of calcium and barium we must therefore take into account not only their influence on the glandular tissue, but also their effect on the muscular tissue of the body. In all cases these salts are antagonistic in their action; and their influence on the secretory activity of the kidney and on the flow of urine is entirely analogous to their influence on the glandular and muscular activities of the intestine. With regard to its action on the kidney calcium chloride may be properly termed an antidiuretic.

Attention must be again called to the extremely poisonous nature of barium chloride. A subcutaneous injection of $3 \mathrm{cc} \mathrm{m} / 8 \mathrm{BaCl}_{2}$ solution is usually sufficient to kill a rabbit. Intravenously it should always be injected with four or five times its volume of $\mathrm{m} / \mathrm{s} \mathrm{NaCl}$ solution.

CONCLUSIONS.

I. In dogs and rabbits the quantity of urine secreted in a unit of time may for a time be markedly diminished and in some cases almost entirely inhibited by the introduction of calcium chloride into the circulation. 
2. Calcium chloride diminishes not only the normal flow of urine, but also that which is caused by the administration of saline diuretics. For example, the rate of secretion which has been largely increased by the intravenous injection of normal salt solution may be temporarily lessened to a marked extent by the introduction of $\mathrm{CaCl}_{2}$ into the blood.

3. In all cases $\mathrm{m} / \mathrm{s}$ solutions were used, and $\mathrm{m} / 8 \mathrm{NaCl}$ solution was introduced into the blood at a constant rate throughout the experiments. After a short time the rate of secretion became constant. It was then found in rabbits, that the addition of a small quantity of $\mathrm{BaCl}_{2}(\mathrm{I} / 8 \mathrm{cc} \mathrm{m} / \mathrm{s}$ solution) to the blood causes a marked increase in the flow of urine, so that the amount of fluid secreted may considerably exceed that which is introduced into the blood during the same period of time.

4. This action of barium is counteracted by the injection of $\mathrm{CaCl}_{2}$.

5. If a larger quantity of $\mathrm{BaCl}_{2}$ ( $\mathrm{I} \mathrm{cc} \mathrm{m} / 8$ solution) be added to the blood, the flow of urine ceases and often complete anuria ensues. In some cases the injection of $\mathrm{CaCl}_{2}$ abolishes this inhibitory action so that the urine flows again. Usually however the action of barium persists.

6. The fact that barium when given in smaller and in larger doses may thus apparently have opposite effects on the flow of urine may be explained by analogy with its action on the intestine. Barium chloride causes not only an increase in the secretion of fluid into the intestine, but also active peristaltic movements, and violent local constrictions of the intestine. Similarly very small doses of $\mathrm{BaCl}_{2}$ increase the secretory activity of the kidney. It seems probable however that the cessation of the flow of urine which follows the injection of larger quantities of the salt is due not to an inhibition of secretion, but to the action of the barium on the muscular coats of the urinary passages, especially those of the calyces and pelvis of the kidney and those of the ureter. This action would bring about a constriction of the tubes and a closure of the lumen. The fact that calcium counteracts both effects of the barium supports this explanation. 
7. The influence of calcium and barium on the flow of urine is in every way analogous to their action on the intestine, which I have previously described. The suppression of the urinary secretion by calcium is also analogous to the suppression of twitchings in voluntary muscles by calcium, which has been described by Loeb.

In conclusion it is a pleasure to thank Professor Loeb for the interest which he has taken in these experiments. I am indebted also to Dr. Theo. C. Burnett, who has assisted me in many of the experiments. 